\title{
ROLE OF CALCIUM THERAPY ON URINARY CALCIUM/CREATININE RATIO IN HELTHY PREGNANT WOMEN AND PRE-ECLAMPTIC WOMEN
}

\author{
SABIHA YASMIN MONI ${ }^{1}$, MAMUN UR RASHID ${ }^{2}$, HOSNE ARA BEGUM ${ }^{3}$, SHAHIN ARA ${ }^{4}$, NAZIMUDDIN AHMED \\ Lecturer, Department of Pharmacology, Rajshahi Medical College, Rajshahi ${ }^{1}$, Professor, Department of \\ Pharmacology, Islami Bank Medical College, Rajshahi ${ }^{2}$, Associate professor ${ }^{3}$, Lecturer ${ }^{4}$, Department of \\ Pharmacology Rajshahi Medical College, Rajshahi, Professor, Pharmacology, Rajshahi ${ }^{5}$.
}

\begin{abstract}
The study has been carried out to observe the effect of calcium therapy on urinary calcium/creatinine ratio in healthy gravid women and pre-eclamptic women. Calcium/creatinine ratio has been considered for early detection of pre-eclamptic toxaemia (PET). So for the diagnosis of PET we try to investigate relation of urinary calcium, urinary creatinine, urinary calcium/creatinine ratio before and after calcium therapy. For this purpose total number of 60 healthy gravid and clinically suspected PET women of 2028 weeks of pregnancy having age ranged from, 17-39 years were selected. Of these 30 healthy pregnant women were taken as control group and another clinically diagnosed 30 PET women were taken as observational group. Urinary calcium/creatinine ratio was within normal range in healthy pregnant women and after calcium therapy this ratio was not significantly changed. On the other hand urinary calcium/creatinine ratio in PET women was significantly decreased and this ratio was significantly increased after calcium therapy. These observations suggest that low calcium/creatinine ratio help in early prediction of PET and calcium supplement during pregnancy may reduce the incidence of PET.
\end{abstract}

(Bangladesh J Physiol Pharmacol 2009; 25(1\&2) : 7-9)

\section{INTRODUCTION}

Pre-eclampsia (PET) is a triad of oedema, hypertension and proteinuria occurs mostly in nullipara after $20^{\text {th }}$ week of gestation and most frequently near term. ${ }^{1}$ National basis, incidence of pre-eclampsia is still very high and the most common medical disorder that occurs during pregnancy. ${ }^{2}$ Inspite of different preventive approaches to improve obstetrics care in Bangladesh it constitutes about 5\% of total deliveries and $16 \%$ of the maternal mortality which is equivalent of about 4500 women/year. ${ }^{2,3}$

Clinical sign of pre-eclampsia is considered to be late manifestation of a disease that has been present since the first trimester of gestation, many workers have studies different biochemical parameters during normal pregnancy for early detection of pre-eclampsia but the result and interpretation are not convincing. 4,5,6,7,8

Empirically many gynecologists give calcium supplement to pregnant women, especially in suspected cases of pre-eclampsia. Calcium supplement during pregnancy may reduce the incidence of pre-eclampsia which was suggested by many worker. ${ }^{8,9,10}$ It has been found that increase in urinary albumin and decrease in calcium excretion may be an early marker for prepeclampsia ${ }^{10}$. Urinary calcium/creatinine ratio less than or equal to 0.04 which may be an early marker for useful screening tool in predicting the subsequent development of pre-elceampia 11,12 .

So determination of calcium/creatinine ratio may easily predict the case of PET. Because previously it was reported that 24 hours urine sample can be replaced by

Address of correspondence: Sabiha Yasmin Moni, Lecturer, Rajshahi Medical College, Rajshahi, E-mail:dr.symoni@yahoo.com. a single voided urine. ${ }^{12,13,14}$ But no data is available on this aspect in our country.

Therefore present study has been carried out to evaluate the effect of calcium therapy on urinary calcium/ creatinine ratio in pre-eclamptic women in our country.

\section{MATERIALSAND METHODS}

This is a non-interventional case control study that was carried out on total number of 60 women with age ranged from 17-39 years of them 30 healthy gravid women were taken as control and 30 PET women were taken as observational group.

All the subjects were selected from department of obstetrics \& gynecology, out door \& indoor, Rajshahi Medical College Hospital. A complete obstetrical history, clinical examination and necessary investigations were done to exclude other conditions affecting urinary calcium/ creatinine ratio. All the subjects were taken from middle and lower middle socioeconomic classes.

The suspected PET women those who had lower urinary calcium/creatinine ratio were supplemented by calcium tablet (1gm/day) for 1 month. ${ }^{15,} 16$

Urinary calcium, urinary creatinine and urinary calcium/creatinine ratio were determined by using reagent kits Human \& Tradesworth germany. Calcium was measured by o-cersolpthelein complexions method \& creatinine was measured by alkaline picrate method of Jaffe. ${ }^{17,} 18$ The significance of differences between two groups was calculated using unpaired student's t test.

\section{RESULTS}

In case of healthy pregnant women (control group) urinary calcium, urinary creatinine and urinary calcium/ 
Bangladesh Journal of Physiology and Pharmacology

Table

Biochemical Result of Urinary Calcium, Urinary Creatinine and Urinary Calcium/Creatinine ratio

\begin{tabular}{|c|c|c|c|c|c|}
\hline \multirow[t]{3}{*}{ Biochemical parameters } & \multicolumn{4}{|c|}{ Calcium therapy $(n=30)$} & \multirow{3}{*}{$\begin{array}{r}P \text { value } \\
<0.001^{\star \star \star}< \\
0.05^{\star}\end{array}$} \\
\hline & \multicolumn{2}{|c|}{ Before } & \multicolumn{2}{|c|}{ After } & \\
\hline & Mean & \pm SEM & Mean & \pm SEM & \\
\hline \multicolumn{6}{|l|}{ Group I (control group) } \\
\hline Urinary Calcium mg/dl & 6.239 & \pm .159 & 12.691 & \pm .536 & NS \\
\hline Urinary Creatinine mg/dl & 33.515 & \pm 2.717 & 81.190 & \pm 8.200 & NS \\
\hline Urinary Calcium/creatinine ratio & .231 & \pm .025 & .200 & \pm .012 & NS \\
\hline \multicolumn{6}{|l|}{ Group II (observational group) } \\
\hline Urinary Calcium mg/dl & 2.581 & \pm .287 & 6.924 & \pm .321 & *** \\
\hline Urinary Creatinine mg/dl & 70.454 & \pm 10.791 & 36.047 & \pm 2.755 & NS \\
\hline Urinary Calcium/creatinine ratio & .136 & \pm .088 & .226 & \pm .020 & $* * *$ \\
\hline
\end{tabular}

creatinine ratio were (mean \pm SEM) $6.239 \pm 0.159 \mathrm{mg} / \mathrm{dl}$, $33.515 \pm 2.717 \mathrm{mg} / \mathrm{dl}$ and $0.231 \pm 0.025$ respectively before calcium therapy. After calcium therapy, urinary calcium, urinary creatinine and urinary calcium/creatinine ratio were $12.691 \pm 0.536 \mathrm{mg} / \mathrm{dl}$ (mean \pm SEM) 81.190 \pm 8.200 $\mathrm{mg} / \mathrm{dl}$ and $0.200 \pm 0.012$ respectively. Calcium therapy did not produce any significant change in calcium/creatinine ratio.

In case of pre-eclamptic women (observational group) urinary calcium,urinary creatinine and urinary calcium/creatinine ratio were (mean \pm SEM) $2.581 \pm 0.287$ $\mathrm{mg} / \mathrm{dl} 70.454 \pm 10.791 \mathrm{mg} / \mathrm{dl}$ and $0.136 \pm .088$ respectively before therapy. After calcium therapy urinary calcium, urinary creatinine and urinary calcium/creatinine ratio were (mean \pm SEM) $6.924 \pm 0.321 \mathrm{mg} / \mathrm{dl} 36.047 \pm 2.755 \mathrm{mg} /$ $\mathrm{dl}$ and $0.226 \pm 0.020$ respectively. Calcium therapy produced highly significant $(P<0.001)$ increase in calcium/creatinine ratio. So calcium therapy was found to have a positive role for prevention of pre-eclampsia.

\section{DISCUSSION}

The present study has been designed to observe the role of calcium on urinary calcium creatinine ratio in healthy pregnant and PET women. PET patient have been shown to excrete less calcium in urine. Several studies have used the predictive value of hypocalciuria for preeclampsia.4,5,11,12,19,20,21,22

In healthy pregnant women (control group) urinary calcium /creatinine ratio was increased after calcium therapy (1gm/day for 1 month) but the change was not statistically significant. This finding is in agreement with another study. ${ }^{8,9}$ In PET women (observational group) urinary calcium/creatinine ratio was significantly increased after calcium therapy (1gm/day for 1 month).
This finding is also well correlated with different workers' findings. ${ }^{6,20,21,22,23,24}$

It was concluded that the urinary calcium/creatinine ratio differ significantly between healthy pregnant women and PET women. So it has been strongly suggested that a high dose calcium intake can correct calcium deficiency which is responsible for development of PET.

This study does not explain the exact mechanism of calcium excretion in urine in PET women. However the mechanism of calcium excretion can be suggested as follows. Large dose of calcium intake increases serum calcium level which lowers parathyroid hormone concentration and reduction of renal calcium reabsorption which ultimately causes increased urinary calcium excretion in $\mathrm{PET}^{25}$. Early prediction of a high-risk pregnancy would allow designing close follow-up plans and calcium supplementation prevent the development of PET. Further studies are needed to clarify the significance of dietary calcium intake and the effectiveness of calcium therapy in PET women.

\section{REFERENCES}

1. Mabie WC and Sibai BM . Hypertensive State of pregnancy. Current Obstetrical and Gynecologic Diagnosis and Treatment. $8^{\text {th }}$ ed. Decherney AH and Pernoll ML (eds), Appleton \& Lange, USA 1994; 380-95.

2. Fauvcau V, Kocning MA. and Chakrobarty J. Causes of Maternal mortality in rural Bangladesh; Bulletin of WHO 1988; 66:643-51.

3. Chesley L. National High Blood Pressure Education program working group report on high blood pressure in pregrancy. Am J Obstet Gynecol 1990; 163: 1697.

4. Huikeshoven FJM. and Zuiderhoudt FMJ. Hypocalciuria in hypertensive disorder in pregnancy and how to measure it. Euro J Obstet Gynaco Repro Biol 1990; 36: 81-85. 
5. Nahid Y.Study of urinary calcium excretion in preecampsia. MS Thesis. Dept. of Obstet. and Gynae, IPGMR, Dhaka, Bangladesh 1997: 6-31.

6. Tkazerooni S. and Hamze-Nejadi S. Calcium to creatnine ratio is a spot sample of urine for early prediction of preeclampsia. Intl J Gynecol Obstet 2003;80: 279-83.

7. Redman. Pre-eclampsia the facts. Oxford medical Publications 1992: 95-97.

8. Belizan Jm, Villar J and Repke J. The relationship between calcium intake and pregnancy induced hypertension: upto date evidence. Am J Obstet Gynecol 1988: 158-899.

9. Taufield PA, Ales KL, Resnick LM, Drozin ML, Gertner J. M and Laragh J. H. Hypocalciuria in preeclampsia. N Engl J Med 1987; 316: 715-18.

10. Hux YR, Yang Z, Zhonghua F, Chan K. ZZ Calcium metabolism in preeclampsia. Int J Gynaecol Obstet 1999; 66(3):245-50.

11. Rodriguez MH, Masari DI, Mestman J, Kumar D. and Rude R. Calcium to creatinine ratio and microalbuminuria in the prediction of preeclampsia. Am J Obstet Gynecol 1988; 158:1425-28.

12. Izumi A, Minarani H, Ruwata T. and Sato I. Calcium to creatinine ratio on spot urine sample in early pregnancy and relation to the development of preeclampsia. Metabolism 1997; 46:1107-08.

13. Poulsen PL. Early renal involvement in type 1 diabetes blood pressure and cardiae autonomic function in relation to risk factors and treatment perspectives. JRAAS 2002; 3:222-4.

14. Wa.A. YT. Tan CB et., al. Microalbuminuria prevalence study in hypertensive patients with type to Diabetes mellitus in Singapore. Singapore med J 2006;47(4):31520.
15. Belizan JM. Preliminary evidence of the effect of calcium supplementation on blood pressure in normal pregnant women. A M J Obstet. Gynecol. 1987; 146:175.

16. Lopez A. Dietary calcium supplementation and prevention of pregnancy hypertension. The Lancet. 1990;335: 293.

17. Bulter A.R. Clin Chim Acta; 59:227 cited from verly practical clinical Boichemistry $6^{\text {th }}$ ed. ALAn H.G.OWen lock., 1975:604-8.

18. Human Gesellschaft fur Biochemica and Diagnostica mbH Mzx -Planck-Ring 21-D-65205 Wiesbaden -Germany. 2007.

19. Sanchez-Ramos L, Jones DC, Gullen MT. Urinary calcium as an early marker for pre-eclampsia. Obstet Gynecol 1991; 77:685-88.

20. Ozcan T. and Kaleli B. Urinary calcium to creatinine ratio for predicting preeclampsia. Am J Perinatol 1995; 12:34951.

21. Conde-Agudelo A, Belizan JM, and Lede R. Prediction of hypertensive disorder of pregnancy by calcium to creatinine ratio and other laboratory tests. Int J Gynecol Obstet1994; 47:285-86.

22. Frenkel $Y$, Barkai G, and Mashiach G. Hypocalciuria of preeclampsia is independent of parathyroid hormone level. Obstet Gynecol 1991; 77:689-91.

23. Seely EW, Wood RJ, Brown EM and Gravos SW.Lower serum ionized calcium and abnormal calcitropic hormone level in pre-eclampsia. J Clin Endocrinol Metab1992; 74:1436-40.

24. Saudan PJ, Shaw $L$ and Brown MA. Urinary calcium to creatinine ratio as a predictor of preeclampsia. Am J Hypertens 1998; 11: 839-43.

25. Davey DA. Hypertensive disorders of pregnancy. Dewhursts Text Book of obstetrics and gynaecology for post graduates 5th ed. Whitfield GR(eds), Black Well, Scientific publications Oxford 1995; 175-85. 